\title{
The Clinical and Metabolic Effects of Intragastric Balloon on Morbid Obesity and Its Related Comorbidities
}

\author{
Joon Hyun Cho ${ }^{1}$, Mohammad Bilal ${ }^{2}$, Min Cheol Kim ${ }^{1}$, Jonah Cohen ${ }^{2}$, and The Study Group for Endoscopic Bariatric and Metabolic \\ Therapies of the Korean Society of Gastrointestinal Endoscopy
}

${ }^{1}$ Division of Gastroenterology and Hepatology, Department of Internal Medicine, Yeungnam University College of Medicine, Daegu, Korea, ${ }^{2}$ Center for Advanced Endoscopy, Division of Gastroenterology, Beth Israel Deaconess Medical Center, Harvard Medical School, Boston, MA, USA

Obesity is becoming increasingly prevalent worldwide, and its metabolic sequelae lead to a significant burden on healthcare resources. Options for the management of obesity include lifestyle modification, pharmacological treatment, surgery, and endoscopic bariatric therapies (EBTs). Among these, EBTs are more effective than diet and lifestyle modification and are less invasive than bariatric surgery. In recent years, there have been significant advances in technologies pertaining to EBTs. Of all the available EBTs, there is a significant amount of clinical experience and published data regarding intragastric balloons (IGBs) because of their comparatively long development period. Currently, the United States Food and Drug Administration (FDA) has approved three IGBs, including Orbera (Apollo Endosurgery, Austin, TX, USA), ReShape Duo (ReShape Medical, San Clemente, CA, USA), and Obalon (Obalon Therapeutics, Carlsbad, CA, USA). The aim of this review is to summarize the available literature on the efficacy of IGBs in weight loss and their impact on obesity-related metabolic diseases. Clin Endosc 2021;54:9-16

Key Words: Bariatrics; Endoscopy; Intragastric balloon; Metabolic; Obesity

\section{INTRODUCTION}

Obesity is a highly prevalent chronic condition that represents a public health problem worldwide, and it is likely that this situation will persist in the future. ${ }^{1}$ The clinical importance of obesity is not limited to the condition itself, but the related comorbidities associated with obesity, such as diabetes mellitus, hyperlipidemia, non-alcoholic fatty liver disease (NAFLD), hypertension, cardiac disease, cerebrovascular diseases, and metabolic syndrome. ${ }^{2}$ Furthermore, obesity is also associated

Received: November 18, 2020 Revised: January 10, 2021

Accepted: January 12, 2021

Correspondence: Jonah Cohen

Division of Gastroenterology, Beth Israel Deaconess Medical Center, Harvard Medical School, 330 Brookline Avenue, Dana 501, Boston, MA 02215, USA

Tel: +1-617-667-2128, Fax: +1-617-667-2767, E-mail: jmcohen@bidmc.harvard.edu ORCID: https://orcid.org/0000-0001-9630-0531

It is the invited review article.

(c) This is an Open Access article distributed under the terms of the Creative Commons Attribution Non-Commercial License (http://creativecommons.org/ licenses/by-nc/3.0) which permits unrestricted non-commercial use, distribution, and reproduction in any medium, provided the original work is properly cited. with an increased risk of all-cause mortality., ${ }^{3,4}$ However, the management of obesity is complex and requires a multifaceted approach. Majority of patients with obesity fail to achieve sustained weight reduction or maintain optimal weight by dietary and lifestyle modifications and pharmacological therapies alone.

Among the several modalities used in managing obesity, the most successful effective long-term options for weight loss are bariatric surgeries such as sleeve gastrectomy and Roux-en-Y gastric bypass, which report a $55 \%$ to $85 \%$ excess weight loss (EWL) ${ }^{5,6}$ However, these surgical interventions have reported mortality rates ranging from $0.2 \%$ to $1.0 \%$, re-intervention rates of $4.3 \%$ to $8.3 \%$, and serious adverse events reported in $26 \%$ of cases. Therefore, very few patients eventually undergo bariatric surgery to manage their obesity and its associated metabolic conditions. Hence, there has been growing interest in endoscopic bariatric and metabolic therapies (EBMTs) over the past decade. EBMT devices are designed such that they are not only efficacious in weight loss, but also have potential for reversibility and are cost-effective when compared to bariatric surgery. ${ }^{8}$ The main mechanisms of EBMT include space occu- 
pation, reducing gastric capacity, modification of gastric motor function, and malabsorption. Among the several EBMTs that have been developed, the intragastric balloons (IGBs) are the most widely used in clinical practice.

Although many methods of bariatric therapies have been developed to date, the ultimate goal of managing obesity is to correct the associated metabolic disease rather than weight loss itself. This review will discuss the various available IGBs, focusing on their effect on weight loss and the improvement in obesity-related complications and metabolic diseases.

\section{INTRAGASTRIC BALLOONS}

IGBs are devices that occupy space in the stomach to induce early satiety. Prior studies suggest that an IGB volume of at least $400 \mathrm{~mL}$ is required for proper weight reduction. ${ }^{9}$ Weight loss after placement of an IGB occurs due to delayed gastric emptying as well as restricted food intake due to the decreased stomach volume. In addition, stretching of the stomach wall stimulates the vagus nerve receptors and brain centers responsible for satiety. ${ }^{10}$ Also, changes in the activity of gastrointestinal hormones and neuropeptides that affect appetite control play a crucial role. However, the exact mechanisms remain unclear.

Although this technique was introduced in the $1980 \mathrm{~s},{ }^{11}$ it was withdrawn from commercial use due to ineffective weight loss, spontaneous balloon deflation, and device-related complications such as gastric ulcers, gastric perforations, and intestinal obstructions that require surgical intervention. ${ }^{12}$ Since then, there have been significant advances in technology (e.g., the use of more durable silicone-based materials), and several IGBs have been used in the clinical setting for more than 25 years. To date, the United States Food and Drug Administration (FDA) has approved three types of IGBs, ${ }^{13-15}$ while several others are in process for approval.

Of these balloon devices, Orbera ${ }^{\mathrm{TM}}$ (Apollo Endosurgery, Austin, TX, USA; Fig. 1A), also formerly known as the BioEnterics Intragastric Balloon, is the most widely available worldwide. Since its introduction in 1996, this type of balloon has been utilized in over 250,000 patients and was approved by the United States FDA in $2015 .^{13}$ The balloon is placed endoscopically into the gastric lumen and filled with 400-700 $\mathrm{mL}$ of sterile saline. An optional $10 \mathrm{~mL}$ of methylene blue may also be added to aid in detection of spontaneous balloon perforation and deflation. The balloon is resistant to gastric acid and is indicated for insertion for up to six months. ReShape Duo $^{\text {TM }}$ (ReShape Medical, San Clemente, CA, USA; Fig. 1B), a dual balloon system, was approved at the same time. ${ }^{14}$ This device contains two balloons that are interconnected by a flexible wire, which minimizes the risk of migration when one balloon deflates. Obalon ${ }^{\mathrm{TM}}$ (Obalon Therapeutics, Carlsbad, CA, USA; Fig. 1C), which was approved by the FDA in $2016,{ }^{15}$ is characterized by its gas-filled design and the ability to be inserted via swallowing the deflated balloon in its capsule form under fluoroscopic guidance. A maximum of three balloons can be placed in the stomach due to a smaller balloon capacity of 250 $\mathrm{mL}$. All three FDA-approved IGBs are indicated for patients with a body mass index (BMI) of 30 to $40 \mathrm{~kg} / \mathrm{m}^{2}$ (class I and II obesity) who have failed to respond to lifestyle modifications and nutritional interventions. Additionally, the ReShape Duo is only indicated for patients with an existing obesity-related comorbidity (i.e., diabetes mellitus, hypertension, hyperlipidemia), ${ }^{16}$ whereas the Orbera does not have this requirement. Until recently, no other effective bariatric procedure could be applied to patients in this group, since patients with a BMI greater than $40 \mathrm{~kg} / \mathrm{m}^{2}$ or BMI $35-40 \mathrm{~kg} / \mathrm{m}^{2}$ with obesity-related comorbidities are generally considered for bariatric surgery.

In recent years, several other IGBs have been developed for weight reduction, such as Spatz Balloon (Spatz FGIA, Great Neck, NY, USA), ${ }^{17}$ Elipse $^{\mathrm{TM}}$ Balloon (Allurion Technologies, Wellesley, MA, USA), ${ }^{18,19}$ Heliosphere BAG (Helioscopie Medical Implants, Vienne, France), ${ }^{20}$ Medsil $^{\circledR}$ (CSC MEDSIL, Moskovskaya oblast, Russia), ${ }^{21}$ LexBal (Lexel Medical, Buenos Aires, Argentina), ${ }^{22}$ and End-ball (Endalis, Brignais, France), ${ }^{23}$ all of which are awaiting FDA approval; further clinical studies with IGBs are expected. Spatz3 (Fig. 1D) is another fluid-filled silicone balloon. This balloon was developed to overcome several limitations of earlier balloons, such as short-term implantation and difficulty in balloon volume adjustment. One of the main advantages of this balloon is its adjustability, making it easier to tailor volumes according to patient tolerance and weight loss. Additionally, Spatz3 is the only IGB that can be left in place for up to 12 months among the currently available IGBs. The Elipse (Fig. 1E) is the first procedureless IGB that does not require endoscopy to place or remove it. ${ }^{19}$ It is a swallowable saline-filled balloon, similar to the Obalon, though it self-deflates by natural degradation of the soluble substance inside the balloon and is naturally excreted through the gastrointestinal tract after approximately 16 weeks. The Heliosphere BAG (Fig. 1F) is an air-filled polyurethane balloon covered with a silicone envelope. Fluid-filled balloons have been reported to frequently induce nausea and vomiting after the time of balloon insertion due to excess balloon weight, and they may be associated with a higher rate of intolerance and early removal. ${ }^{24}$ Thus, this air-filled device was introduced to avoid these disadvantages. The End-ball (Fig. 1G) is a saline/ air-filled polyurethane balloon and is the most commonly used IGB in Korea. ${ }^{25}$ Conventional IGBs are filled with either saline or air, each with their respective advantages and disad- 

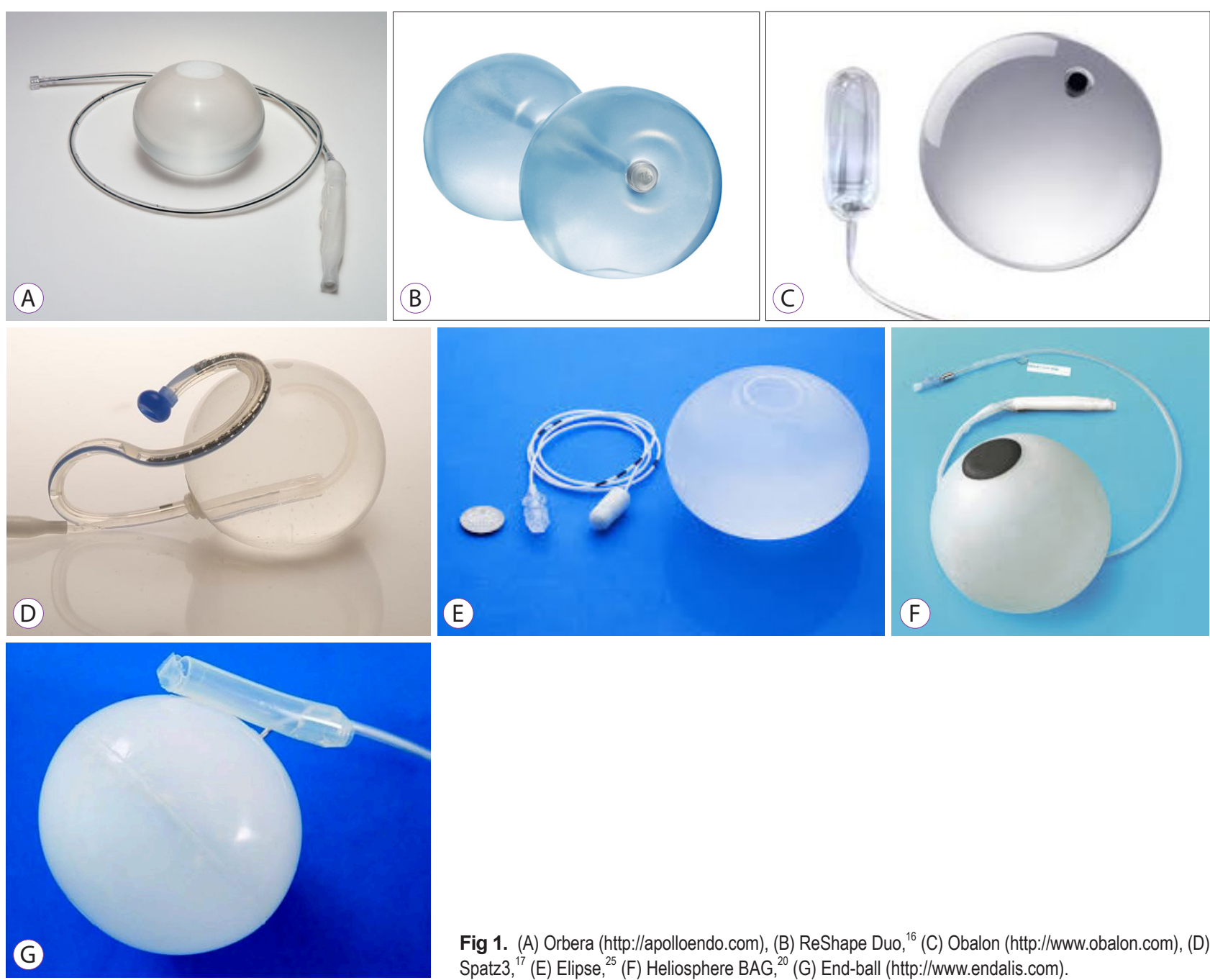

Fig 1. (A) Orbera (http://apolloendo.com), (B) ReShape Duo, ${ }^{16}$ (C) Obalon (http://www.obalon.com), (D) Spatz $3,{ }^{17}$ (E) Elipse, ${ }^{25}$ (F) Heliosphere BAG,${ }^{20}$ (G) End-ball (http://www.endalis.com).

vantages. Air-filled balloons are well tolerated but less effective in terms of weight loss, while saline-filled balloons are more effective with regard to weight loss, but are associated with more adverse events. ${ }^{24,26}$ The unique feature of the End-ball is that the endoscopist can select the saline-to-air ratio in the balloon for infusion.

\section{CHARACTERISTICS OF INTRA-GASTRIC BALLOONS WITH FDA APPROVAL OR IN THE PROCESS OF FDA APPROVAL}

\section{Orbera (Apollo Endosurgery, Austin, TX, USA); FDA-approved}

(1) Silicone, single balloon filled with $400-700 \mathrm{~mL}$ of saline
(2) Endoscopic placement / Endoscopic removal after deflation

(3) Implanted for up to a maximum of 6 months

ReShape Duo (ReShape Medical, San Clemente, CA, USA); FDA-approved

(1) Silicone, double balloon filled with $450 \mathrm{~mL}$ of saline per balloon

(2) Endoscopic placement / Endoscopic removal after deflation

(3) Implanted for up to a maximum of 6 months

Obalon (Obalon Therapeutics, Carlsbad, CA, USA); FDA-approved

(1) Gelatin capsule, up to 3 balloons filled with $250 \mathrm{~mL}$ of gas 
(2) Insertion via swallowing in capsule form, verification of gastric location done via fluoroscopy or pressure reading/endoscopic removal with deflation

(3) Implanted for 3-6 months

\section{Spatz (Spatz FGIA, Great Neck, NY, USA); not FDA- approved}

(1) Silicone, single adjustable balloon filled with $400-800$ $\mathrm{mL}$ of saline

(2) Endoscopic placement / Endoscopic adjustment of fill volume / Endoscopic removal

(3) Implanted for up to a maximum of 12 months

\section{Elipse (Allurion Technologies, Wellesley, MA, USA); not FDA-approved}

(1) Polymer film, single balloon filled with $450-550 \mathrm{~mL}$ of saline

(2) Insertion via swallowing in capsule form, verification of gastric location done via fluoroscopy or pressure reading/degradation and excretion naturally through the GI tract at 4 months with complete deflation

\section{Heliosphere BAG (Helioscopie Medical Implants, Vienne, France); not FDA-approved}

(1) Polyurethane and silicone, single balloon filled with 550 $\mathrm{mL}$ of air

(2) Endoscopic placement / Endoscopic removal

(3) Implanted for up to a maximum of 6 months

\section{End-ball (Endalis, Brignais, France); not FDA- approved}

(1) Polyurethane, single balloon filled with $600 \mathrm{~mL}$ of air/ saline; endoscopist can select any ratio of air to saline for infusion

(2) Endoscopic placement / Endoscopic removal after deflation

(3) Implanted for up to a maximum of 6 months

\section{WEIGHT LOSS AND METABOLIC EFFECTS OF INTRA-GASTRIC BALLOONS}

The goal of an IGB is to induce weight reduction and assist with the management of obesity-related comorbidities, with adequate safety. An IGB is suitable for patients with a BMI of $30-40 \mathrm{~kg} / \mathrm{m}^{2}$ (class I and II obesity). ${ }^{27}$ In patients with severe or morbid obesity (BMI $>40 \mathrm{~kg} / \mathrm{m}^{2}$ to $>50 \mathrm{~kg} / \mathrm{m}^{2}$, class III and IV obesity), IGB placement can help in preparation for bariatric surgery by reducing the surgical risk or facilitate non- bariatric interventions that could not be safely performed due to weight limits (i.e., orthopedic surgery, organ transplantation). ${ }^{28-36}$

Prior to its recent FDA approval, the weight loss effect of IGB was proven through early clinical studies in Europe. A retrospective study of 2,515 cases conducted in Italy, which has been one of the largest until now, demonstrated a mean BMI loss of $4.9 \pm 12 \mathrm{~kg} / \mathrm{m}^{2}$ over the 6-month study period. ${ }^{37}$ Furthermore, $44.3 \%$ of obesity-related complications, including hypertension, diabetes mellitus, dyslipidemia, respiratory disorder, and osteoarthropathy, resolved and another $44.8 \%$ of them improved during the study period. In one meta-analy$\mathrm{sis}^{38}$ of 16 studies involving 3,608 patients who underwent IGB placement, there was a reported mean BMI loss of $5.7 \mathrm{~kg} / \mathrm{m}^{2}$ and a $\% \mathrm{EWL}$ of $32.1 \%$ at the time of balloon removal. Additionally, obesity-related complications, including hypertension, diabetes mellitus, and dyslipidemia, also improved. These positive outcomes have also been reported with a \%EWL range of $34 \%-50 \%$ in several prospective randomized controlled studies (RCTs) comparing IGB (Orbera) to dietary and lifestyle interventions (Table 1). ${ }^{39-43}$ Furthermore, IGBs have also been shown to be superior in weight reduction to pharmacological therapies, and similar to laparoscopic adjustable gastric banding. ${ }^{44}$ The other FDA-approved IGBs, Reshape Duo and Obalon, also have similar weight loss effects. ${ }^{45,46}$

More recently, four systematic reviews and meta-analyses on the efficacy of weight loss with IGBs have been published. The first meta-analysis, which included 1,683 patients in 17 studies using the Orbera, demonstrated a mean \%EWL of $25.44 \%$, and the results met the American Society for Gastrointestinal Endoscopy (ASGE) PIVI criteria of 25\% EWL. ${ }^{29}$ In the second meta-analysis, Moura et al. ${ }^{47}$ reviewed nine studies involving 669 patients using either the Orbera, Reshape Duo, or air-filled balloons, which compared IGB plus diet to sham plus diet. They found a mean \%EWL of $14 \%$ favoring the IGB group. The third meta-analysis involving 20 studies with 1195 patients demonstrated a similar \%EWL of $14.2 \%$ at 3 months after IGB placement. ${ }^{48}$ In another meta-analysis, Kotinda et al. ${ }^{49}$ reviewed 13 RCTs involving 1,523 patients using either the Orbera, Reshape Duo, Obalon, Spatz, or Heliosphere, which compared IGB with sham or lifestyle intervention, and showed that the difference in mean \%EWL and \% total weight loss (\%TWL) at follow-up was $17.9 \%$, and $4.4 \%$, respectively, and was significantly higher in the IGB group. Singh et al. also conducted a systematic review and meta-analysis comparing the efficacy, safety, and durability of IGB versus endoscopic sleeve gastroplasty (ESG). ${ }^{50}$ They found that the mean \%TWL at 12-month follow-up with ESG was $17.5 \%$ as compared to $10.3 \%$ with IGB placement. ${ }^{50}$ 
Table 1. Prospective, Randomized Controlled Trials of Intragastric Balloons

\begin{tabular}{|c|c|c|c|c|c|c|c|c|c|}
\hline & & & & & Number of subjects & & & & \\
\hline IGB device & Study & Country & $\begin{array}{c}\text { implant } \\
\text { time } \\
\text { (wk) }\end{array}$ & $\begin{array}{c}n \\
\text { (total) }\end{array}$ & Study arm & \%EWL & \%TBWL & $\begin{array}{c}\text { BMI loss } \\
\left(\mathrm{kg} / \mathrm{m}^{2}\right)\end{array}$ & $p$-value \\
\hline Orbera & $\begin{array}{l}\text { Genco et al. } \\
(2006)^{39}\end{array}$ & Italy & 12 & 32 & $\begin{array}{l}16(\mathrm{IGB}+ \\
16 \text { (sham }\end{array}$ & $\begin{array}{c}34.0 \pm 4.8 \\
2.1 \pm 1.0\end{array}$ & NR & $\begin{array}{l}5.8 \pm 0.5 \\
0.4 \pm 0.2\end{array}$ & $\begin{array}{c}<0.001 \\
(\% \mathrm{EWL})\end{array}$ \\
\hline Orbera & $\begin{array}{l}\text { Konop- } \\
\text { ko-Zubrzy- } \\
\text { cka et al. } \\
(2009)^{40}\end{array}$ & Poland & 24 & 36 & $\begin{array}{c}21 \text { (IGB) } \\
15 \text { (diet + exercises) }\end{array}$ & NR & $\begin{array}{c}12.3 \\
2.3\end{array}$ & NR & $<0.001$ \\
\hline Orbera & $\begin{array}{l}\text { Peker et al. } \\
(2011)^{44}\end{array}$ & Turkey & 24 & 32 & $\begin{array}{c}16(\mathrm{IGB}) \\
16 \text { (laparoscopic band) }\end{array}$ & $\begin{array}{l}39.3 \\
32.3\end{array}$ & NR & NR & 0.189 \\
\hline Orbera & $\begin{array}{l}\text { Farina et al. } \\
(2012)^{41}\end{array}$ & Italy & 24 & 50 & $\begin{array}{c}30(\mathrm{IGB}+\text { diet }+ \text { exercise }) \\
20 \text { (sibutramine + diet }+ \text { exercise })\end{array}$ & NR & $\begin{array}{c}14.5 \pm 1.2 \\
9.1 \pm 1.5\end{array}$ & NR & $<0.05$ \\
\hline Orbera & $\begin{array}{l}\text { Lee et al. } \\
(2012)^{42}\end{array}$ & Singapore & 24 & 18 & $\begin{array}{c}8(\text { IGB + diet + exercise }) \\
10(\text { sham + diet + exercise })\end{array}$ & NR & NR & $\begin{array}{l}1.69 \pm 0.89 \\
0.54 \pm 0.54\end{array}$ & $<0.001$ \\
\hline Orbera & $\begin{array}{l}\text { Fuller et al. } \\
(2013)^{43}\end{array}$ & Australia & 24 & 66 & $\begin{array}{l}31 \text { (IGB + behavioral modification) } \\
35 \text { (behavioral modification alone) }\end{array}$ & $\begin{array}{l}50.3 \\
16.9\end{array}$ & $\begin{array}{c}14.2 \\
4.8\end{array}$ & $\begin{array}{l}5.1 \\
1.7\end{array}$ & $\begin{array}{c}<0.001 \\
(\% \mathrm{EWL})\end{array}$ \\
\hline Rehape Duo & $\begin{array}{l}\text { Ponce et al. } \\
(2015)^{45}\end{array}$ & USA & 24 & 326 & $\begin{array}{c}187(\text { IGB + diet + exercise }) \\
139(\text { sham + diet + exercise })\end{array}$ & $\begin{array}{l}25.1 \pm 1.6 \\
11.3 \pm 1.9\end{array}$ & $\begin{array}{l}7.6 \pm 5.5 \\
3.6 \pm 6.3\end{array}$ & $\begin{array}{l}2.7 \pm 1.9 \\
1.3 \pm 2.3\end{array}$ & $\begin{array}{c}0.004 \\
(\% \mathrm{EWL})\end{array}$ \\
\hline Obalon & $\begin{array}{l}\text { Sullivan et } \\
\text { al. }(2018)^{46}\end{array}$ & USA & 24 & 387 & $\begin{array}{c}198(\text { IGB + exercise }) \\
189 \text { (sham + exercise })\end{array}$ & $\begin{array}{l}23.9 \pm 19.2 \\
12.4 \pm 18.8\end{array}$ & $\begin{array}{l}6.6 \pm 5.1 \\
3.4 \pm 5.0\end{array}$ & $\begin{array}{l}2.3 \pm 1.8 \\
1.2 \pm 1.8\end{array}$ & $\begin{array}{c}<0.001 \\
(\% \mathrm{EWL})\end{array}$ \\
\hline
\end{tabular}

BMI, body mass index; \%EWL, \% excess weight loss; IGB, intragastric balloon; NR, not reported; \%TBWL, \% total body weight loss.

While weight reduction can be achieved significantly by IGB placement, it should be noted that the effect may only be short-term due to regain of weight within one year after removal, as reported in some studies. ${ }^{51} \mathrm{~A}$ long-term outcome after treatment with an IGB and IGB removal ( $4.8 \pm 1.6$ years) was evaluated through a prospective study in Switzerland. ${ }^{52}$ The study reported that only about $1 / 4$ of the patients were able to maintain clinically significant weight loss after IGB removal, and the other $3 / 4$ required additional measures for weight reduction, such as bariatric surgery, repeat IGB placement, or taking sibutramine for short periods. Thus, the main limitation of IGBs is that their impact on long-term weight loss is still unclear. Therefore, several other methods are currently being evaluated, such as combining IGBs (combination therapy in tandem with IGB or as a sequential therapy following IGB removal) not only with dietary and lifestyle modifications and pharmacotherapy but also with other types of endoscopic bariatric therapy that have different weight loss mechanisms.

In addition to effective weight loss, obesity-related comorbid conditions have also been shown to be considerably improved by IGB placement. Several studies have reported substantial improvements in patient condition secondary to IGB placement, as defined by reduction in the required drug doses or mitigation of treatment methods for diseases such as diabetes mellitus, hypertension, and dyslipidemia. ${ }^{53,54}$ NAFLD has also been reported to improve after IGB placement. This has been demonstrated by improvements in liver function tests, steatosis on magnetic resonance imaging scans, and other histologic findings. ${ }^{42,55,56}$ In addition, respiratory disorders have also been reported to improve after Orbera placement, with one study reporting an overall improvement in lung function parameters. ${ }^{57}$ Another study reported that a weight reduction of approximately $15 \%$ of baseline body weight obtained by insertion of an IGB substantially decreased the severity of obstructive sleep apnea in patients with morbid obesity. ${ }^{58}$

Obesity is accompanied by adipose tissue remodeling with adipocyte hypertrophy and alterations in cellular composition that promote a chronic low-grade inflammatory state. ${ }^{59,60}$ This pro-inflammatory state, which is mediated by an unbalanced production of various cytokines and adipokines, seems to play an important role in the development of metabolic disorders, such as insulin resistance. ${ }^{59,61,62}$ Weight reduction achieved by IGB placement, similar to weight reduction obtained by other methods, could have favorable effects on the inflammatory status and metabolic profile, which can in turn decrease the risk of cardiovascular events. A small prospective observa- 
tional study involving 42 patients with obesity using IGB for 6 months found reduced serum levels of leptin and high sensitive C-reactive protein, as well as improved insulin resistance and lipid profile, which may decrease cardiovascular risk, and adiponectin/leptin ratio. ${ }^{63}$ In spite of the many trials on weight reduction, information regarding the metabolic benefits of IGBs is relatively limited. A meta-analysis of 40 studies that included at least one metabolic parameter and evaluated the effect of IGB placement on metabolic comorbidities, concluded that IGB placement substantially improved fasting blood glucose, hemoglobin A1c, serum triglyceride levels, and blood pressure. Hemoglobin A1c and fasting blood glucose in patients with diabetes mellitus were shown to be decreased by $17 \%$ and $15 \%$, respectively. ${ }^{64}$ The odds ratio for diabetes resolution after IGB placement was 1.4 (95\% confidence interval, 1.3-1.6). Another meta-analysis showed the beneficial effects of IGB placement on the improvement of liver enzymes and NAFLD in patients with obesity. ${ }^{65}$ Thus, IGB can be provided as an additional therapeutic option for obese patients with metabolic syndrome, as part of a multidisciplinary approach to management.

\section{ADVERSE EVENTS}

Patients usually complain of accommodative symptoms during the initial weeks post-placement. The most common adverse event after IGB placement is reported to be nausea and vomiting (23.3\%) and abdominal pain (19.9\%), followed by gastroesophageal reflux (14.3\%), diarrhea or constipation (10.4\%), gastric stasis $(8.3 \%)$, and gastric ulceration $(0.3 \%){ }^{30}$ Early removal of IGB has been reported in $3.5 \%$ of cases and is mostly due to nausea, vomiting, and abdominal pain,. However, several of these symptoms can be managed conservatively without the need for IGB removal. Of these symptoms, aggravation of acid reflux can occur after IGB placement, and up to $7 \%$ of patients may experience reflux symptoms that are severe enough to require early balloon removal. ${ }^{56,66,67}$ This highlights the importance of proton pump inhibitor (PPI) therapy after IGB placement and why patients who are unable to tolerate PPI are not ideal candidates for IGB placement. ${ }^{68}$

Serious adverse events are rare with IGBs. Migration has been reported in $1.4 \%$ of cases, small bowel obstruction in $0.3 \%$, and gastric perforation in $0.1 \%$ of patients. ${ }^{29}$ Few case reports have also demonstrated intestinal obstruction that occurred due to balloon deflation with subsequent distal migration, requiring surgical removal. ${ }^{69-72}$ Although most deflated balloons will be spontaneously expelled from the rectum.

\section{CONCLUSIONS}

The field of EBMT is evolving, and new devices are being rapidly introduced. IGBs are one of the most mature and widely used EBMTs worldwide. Several IGBs are currently available for use in clinical practice, and more devices are in the development phase. IGB placement provides a minimally invasive, safe, and effective method for managing patients with obesity and related metabolic comorbidities. Currently, the use of IGBs is still infrequent in Korea due to cost and accessibility; however, better insurance coverage and reduced costs through non-endoscopic options in the near future may lead to wider availability.

\section{Conflicts of Interest}

Jonah Cohen is a consultant for Boston Scientific. The other authors have no potential conflicts of interest.

Funding

None.

Author Contributions

Supervision: Jonah Cohen

Writing-original draft: Joon Hyun Cho

Writing-review\&editing: JHC, Mohammad Bilal, Min Cheol Kim, JC

ORCID
Joon Hyun Cho:

Mohammad Bilal:

Min Cheol Kim:

Jonah Cohen: https://orcid.org/0000-0002-3584-6300 https://orcid.org/0000-0002-1784-212X https://orcid.org/0000-0002-2234-8070 https://orcid.org/0000-0001-9630-0531

\section{REFERENCES}

1. Kushner RF, Kahan S. Introduction: the state of obesity in 2017. Med Clin North Am 2018;102:1-11.

2. Segula D. Complications of obesity in adults: a short review of the literature. Malawi Med J 2014;26:20-24.

3. Aune D, Sen A, Prasad M, et al. BMI and all cause mortality: systematic review and non-linear dose-response meta-analysis of 230 cohort studies with 3.74 million deaths among 30.3 million participants. BMJ 2016;353:i2156.

4. Global BMI Mortality Collaboration, Di Angelantonio E, Bhupathiraju Sh N, et al. Body-mass index and all-cause mortality: individual-participant-data meta-analysis of 239 prospective studies in four continents. Lancet 2016;388:776-786.

5. Buchwald H, Estok R, Fahrbach K, et al. Weight and type 2 diabetes after bariatric surgery: systematic review and meta-analysis. Am J Med 2009;122:248-256.e5

6. Schauer PR, Kashyap SR, Wolski K, et al. Bariatric surgery versus intensive medical therapy in obese patients with diabetes. N Engl J Med 2012;366:1567-1576.

7. Morino M, Toppino M, Forestieri P, Angrisani L, Allaix ME, Scopinaro N. Mortality after bariatric surgery: analysis of 13,871 morbidly obese patients from a national registry. Ann Surg 2007;246:1002-1007; discussion 1007-1009. 
8. Sullivan S, Edmundowicz SA, Thompson CC. Endoscopic bariatric and metabolic therapies: new and emerging technologies. Gastroenterology 2017;152:1791-1801.

9. Geliebter A, Westreich S, Gage D. Gastric distention by balloon and testmeal intake in obese and lean subjects. Am J Clin Nutr 1988;48:592-594.

10. Stefater MA, Wilson-Pérez HE, Chambers AP, Sandoval DA, Seeley RJ. All bariatric surgeries are not created equal: insights from mechanistic comparisons. Endocr Rev 2012;33:595-622.

11. Nieben OG, Harboe H. Intragastric balloon as an artificial bezoar for treatment of obesity. Lancet 1982;1:198-199.

12. Benjamin SB, Maher KA, Cattau EL Jr, et al. Double-blind controlled trial of the Garren-Edwards gastric bubble: an adjunctive treatment for exogenous obesity. Gastroenterology 1988;95:581-588.

13. US Food and Drug Administration. Summary of safety and effectiveness data (SSED): ORBERA ${ }^{\mathrm{TM}}$ Intragastric Balloon System [Internet]. Silver Spring (MD): FDA; c2015 [updated 2015 Aug 5; cited 2019 Jan 2]. Available from: https://www.accessdata.fda.gov/cdrh_docs/pdf14/P140008b. pdf.

14. US Food and Drug Administration. Summary of safety and effectiveness data (SSED): ReShape ${ }^{\mathrm{TM}}$ Integrated Dual Balloon System [Internet]. Silver Spring (MD): FDA; c2015 [updated 2015 Jul 28; cited 2019 Jan 2]. Available from: https://www.accessdata.fda.gov/cdrh_docs/pdf14/ P140012b.pdf.

15. US Food and Drug Administration. Summary of safety and effectiveness data (SSED): Obalon Balloon System [Internet]. Silver Spring (MD): FDA; c2016 [updated 2016 Sep 8; cited 2019 Jan 2]. Available from: https://www.accessdata.fda.gov/cdrh_docs/pdf16/P160001b.pdf.

16. ReShape ${ }^{\mathrm{TM}}$ integrated dual balloon system instructions for use [Internet]. St. Paul (MN): EnteroMedics Inc.; c2015 [updated 2015 Dec 15]. Available from: https://www.reshapelifesciences.com/wp-content/uploads/2018/02/ReShape_Balloon_ReShape-vBloc_IFU_1-31-18.pdf

17. Machytka E, Klvana P, Kornbluth A, et al. Adjustable intragastric balloons: a 12-month pilot trial in endoscopic weight loss management. Obes Surg 2011;21:1499-1507.

18. Lopasso FP, Sakai P, Gazi BM, et al. A pilot study to evaluate the safety, tolerance, and efficacy of a novel stationary antral balloon (SAB) for obesity. J Clin Gastroenterol 2008;42:48-53.

19. Machytka E, Chuttani R, Bojkova M, et al. Elipse ${ }^{\mathrm{TM}}$, a procedureless gastric balloon for weight loss: a proof-of-concept pilot study. Obes Surg 2016;26:512-516.

20. Trande P, Mussetto A, Mirante VG, et al. Efficacy, tolerance and safety of new intragastric air-filled balloon (Heliosphere BAG) for obesity: the experience of 17 cases. Obes Surg 2010;20:1227-1230.

21. Bužga M, Evžen M, Pavel K, et al. Effects of the intragastric balloon MedSil on weight loss, fat tissue, lipid metabolism, and hormones involved in energy balance. Obes Surg 2014;24:909-915.

22. Żurawiński W, Sokołowski D, Krupa-Kotara K, Czech E, Sosada K. Evaluation of the results of treatment of morbid obesity by the endoscopic intragastric balloon implantation method. Wideochir Inne Tech Maloinwazyjne 2017;12:37-48.

23. Buzga M, Kupka T, Siroky M, et al. Short-term outcomes of the new intragastric balloon End-Ball for treatment of obesity. Wideochir Inne Tech Maloinwazyjne 2016;11:229-235.

24. Bazerbachi F, Haffar S, Sawas T, et al. Fluid-filled versus gas-filled intragastric balloons as obesity interventions: a network meta-analysis of randomized trials. Obes Surg 2018;28:2617-2625.

25. Choi SJ, Choi HS. Various intragastric balloons under clinical investigation. Clin Endosc 2018;51:407-415.

26. Trang J, Lee SS, Miller A, et al. Incidence of nausea and vomiting after intragastric balloon placement in bariatric patients - a systematic review and meta-analysis. Int J Surg 2018;57:22-29.

27. Brill JV. Reimbursement for endoscopic bariatric therapies. Gastrointest Endosc Clin N Am 2017;27:343-351.

28. Doldi SB, Micheletto G, Perrini MN, Librenti MC, Rella S. Treatment of morbid obesity with intragastric balloon in association with diet. Obes Surg 2002;12:583-587.

29. ASGE Bariatric Endoscopy Task Force and ASGE Technology Committee; Abu Dayyeh BK, Kumar N, et al. ASGE Bariatric Endoscopy Task Force systematic review and meta-analysis assessing the ASGE PIVI thresholds for adopting endoscopic bariatric therapies. Gastrointest Endosc 2015;82:425-438.e5.

30. Yorke E, Switzer NJ, Reso A, et al. Intragastric balloon for management of severe obesity: a systematic review. Obes Surg 2016;26:2248-2254.

31. Choudhary NS, Puri R, Saraf N, et al. Intragastric balloon as a novel modality for weight loss in patients with cirrhosis and morbid obesity awaiting liver transplantation. Indian J Gastroenterol 2016;35:113-116.

32. Gentileschi P, Venza M, Benavoli D, et al. Intragastric balloon followed by biliopancreatic diversion in a liver transplant recipient: a case report. Obes Surg 2009;19:1460-1463.

33. Al-Sabah S, Al-Marri F, Vaz JD. Intragastric balloon as a bridge procedure in patients with high body mass index. Surg Obes Relat Dis 2016;12:1900-1901.

34. Coffin B, Maunoury V, Pattou F, et al. Impact of intragastric balloon before laparoscopic gastric bypass on patients with super obesity: a randomized multicenter study. Obes Surg 2017;27:902-909.

35. Frutos MD, Morales MD, Luján J, Hernández Q, Valero G, Parrilla P. Intragastric balloon reduces liver volume in super-obese patients, facilitating subsequent laparoscopic gastric bypass. Obes Surg 2007;17:150154.

36. Storm AC, Lakdawala NK, Thompson CC. Intragastric balloon for management of morbid obesity in a candidate for heart transplantation. J Heart Lung Transplant 2017;36:820-821.

37. Genco A, Bruni T, Doldi SB, et al. BioEnterics intragastric balloon: the Italian experience with 2,515 patients. Obes Surg 2005;15:1161-1164.

38. Imaz I, Martínez-Cervell C, García-Alvarez EE, Sendra-Gutiérrez JM, González-Enríquez J. Safety and effectiveness of the intragastric balloon for obesity. A meta-analysis. Obes Surg 2008;18:841-846.

39. Genco A, Cipriano M, Bacci V, et al. BioEnterics Intragastric Balloon (BIB): a short-term, double-blind, randomised, controlled, crossover study on weight reduction in morbidly obese patients. Int J Obes (Lond) 2006;30:129-133.

40. Konopko-Zubrzycka M, Baniukiewicz A, Wróblewski E, et al. The effect of intragastric balloon on plasma ghrelin, leptin, and adiponectin levels in patients with morbid obesity. J Clin Endocrinol Metab 2009;94:16441649.

41. Farina MG, Baratta R, Nigro A, et al. Intragastric balloon in association with lifestyle and/or pharmacotherapy in the long-term management of obesity. Obes Surg 2012;22:565-571.

42. Lee YM, Low HC, Lim LG, et al. Intragastric balloon significantly improves nonalcoholic fatty liver disease activity score in obese patients with nonalcoholic steatohepatitis: a pilot study. Gastrointest Endosc 2012;76:756-760

43. Fuller NR, Pearson S, Lau NS, et al. An intragastric balloon in the treatment of obese individuals with metabolic syndrome: a randomized controlled study. Obesity (Silver Spring) 2013;21:1561-1570.

44. Peker Y, Coskun H, Bozkurt S, Cin N, Atak T, Genc H. Comparison of results of laparoscopic gastric banding and consecutive intragastric balloon application at 18 months: a clinical prospective study. J Laparoendosc Adv Surg Tech A 2011;21:471-475.

45. Ponce J, Woodman G, Swain J, et al. The REDUCE pivotal trial: a prospective, randomized controlled pivotal trial of a dual intragastric balloon for the treatment of obesity. Surg Obes Relat Dis 2015;11:874-881.

46. Sullivan S, Swain J, Woodman G, et al. Randomized sham-controlled trial of the 6-month swallowable gas-filled intragastric balloon system for weight loss. Surg Obes Relat Dis 2018;14:1876-1889.

47. Moura D, Oliveira J, De Moura EG, et al. Effectiveness of intragastric balloon for obesity: a systematic review and meta-analysis based on randomized control trials. Surg Obes Relat Dis 2016;12:420-429. 
48. Saber AA, Shoar S, Almadani MW, et al. Efficacy of first-time intragastric balloon in weight loss: a systematic review and meta-analysis of randomized controlled trials. Obes Surg 2017;27:277-287.

49. Kotinda A, de Moura DTH, Ribeiro IB, et al. Efficacy of intragastric balloons for weight loss in overweight and obese adults: a systematic review and meta-analysis of randomized controlled trials. Obes Surg 2020;30:2743-2753.

50. Singh S, de Moura DTH, Khan A, et al. Intragastric balloon versus endoscopic sleeve gastroplasty for the treatment of obesity: a systematic review and meta-analysis. Obes Surg 2020;30:3010-3029.

51. Herve J, Wahlen $\mathrm{CH}$, Schaeken A, et al. What becomes of patients one year after the intragastric balloon has been removed? Obes Surg 2005; 15:864-870.

52. Dastis NS, François E, Deviere J, et al. Intragastric balloon for weight loss: results in 100 individuals followed for at least 2.5 years. Endoscopy 2009;41:575-580.

53. Tai CM, Lin HY, Yen YC, et al. Effectiveness of intragastric balloon treatment for obese patients: one-year follow-up after balloon removal. Obes Surg 2013;23:2068-2074

54. Dumonceau JM. Evidence-based review of the Bioenterics intragastric balloon for weight loss. Obes Surg 2008;18:1611-1617.

55. Ricci G, Bersani G, Rossi A, Pigò F, De Fabritiis G, Alvisi V. Bariatric therapy with intragastric balloon improves liver dysfunction and insulin resistance in obese patients. Obes Surg 2008;18:1438-1442.

56. Folini L, Veronelli A, Benetti A, et al. Liver steatosis (LS) evaluated through chemical-shift magnetic resonance imaging liver enzymes in morbid obesity; effect of weight loss obtained with intragastric balloon gastric banding. Acta Diabetol 2014;51:361-368.

57. Mafort TT, Madeira E, Madeira M, et al. Six-month intragastric balloon treatment for obesity improves lung function, body composition, and metabolic syndrome. Obes Surg 2014;24:232-240.

58. Busetto L, Enzi G, Inelmen EM, et al. Obstructive sleep apnea syndrome in morbid obesity: effects of intragastric balloon. Chest 2005;128:618623.

59. Fuster JJ, Ouchi N, Gokce N, Walsh K. Obesity-induced changes in adipose tissue microenvironment and their impact on cardiovascular disease. Circ Res 2016;118:1786-1807.
60. Martyniak K, Masternak MM. Changes in adipose tissue cellular composition during obesity and aging as a cause of metabolic dysregulation. Exp Gerontol 2017;94:59-63.

61. Blüher M. Adipose tissue inflammation: a cause or consequence of obesity-related insulin resistance? Clin Sci (Lond) 2016;130:1603-1614

62. Katsiki N, Mantzoros C, Mikhailidis DP. Adiponectin, lipids and atherosclerosis. Curr Opin Lipidol 2017;28:347-354.

63. Guedes MR, Fittipaldi-Fernandez RJ, Diestel CF, Klein M. Impact of intragastric balloon treatment on adipokines, cytokines, and metabolic profile in obese individuals. Obes Surg 2019;29:2600-2608.

64. Popov VB, Ou A, Schulman AR, Thompson CC. The impact of intragastric balloons on obesity-related co-morbidities: a systematic review and meta-analysis. Am J Gastroenterol 2017;112:429-439.

65. Popov VB, Thompson CC, Kumar N, Ciarleglio MM, Deng Y, Laine L. Effect of intragastric balloons on liver enzymes: a systematic review and meta-analysis. Dig Dis Sci 2016;61:2477-2487.

66. Mathus-Vliegen EM, Tygat GN. Gastro-oesophageal reflux in obese subjects: influence of overweight, weight loss and chronic gastric balloon distension. Scand J Gastroenterol 2002;37:1246-1252.

67. Mathus-Vliegen EM, van Weeren M, van Eerten PV. Los function and obesity: the impact of untreated obesity, weight loss, and chronic gastric balloon distension. Digestion 2003;68:161-168.

68. Rossi A, Bersani G, Ricci G, Petrini C, DeFabritiis G, Alvisi V. Intragastric balloon insertion increases the frequency of erosive esophagitis in obese patients. Obes Surg 2007;17:1346-1349.

69. Kim WY, Kirkpatrick UJ, Moody AP, Wake PN. Large bowel impaction by the BioEnterics Intragastric Balloon (BIB) necessitating surgical intervention. Ann R Coll Surg Engl 2000;82:202-204.

70. Vanden Eynden F, Urbain P. Small intestine gastric balloon impaction treated by laparoscopic surgery. Obes Surg 2001;11:646-648.

71. Lopez-Nava G, Bautista-Castaño I, Jimenez-Baños A, Fernandez-Corbelle JP. Dual intragastric balloon: single ambulatory center Spanish experience with 60 patients in endoscopic weight loss management. Obes Surg 2015;25:2263-2267.

72. Mathus-Vliegen EM, Alders PR, Chuttani R, Scherpenisse J. Outcomes of intragastric balloon placements in a private practice setting. Endoscopy $2015 ; 47: 302-307$. 